\title{
Experimental Determination of Flue Gases Parameters
}

\author{
T. Výtisk \\ Department of Power Engineering \\ Faculty of Mechanical Engineering, \\ Technical University of Ostrava \\ Czech Republic
}

\author{
R. Janalík \\ Department of Power Engineering \\ Faculty of Mechanical Engineering \\ Technical University of Ostrava \\ Czech Republic
}

\begin{abstract}
This article describes a new method of measurement and determination of an average concentration of gaseous components of flue gases at the boiler output, which is based on the use of equipment for continuous network sampling and analysis of gaseous pollutants, developed at the VŠB-TU Ostrava for the purpose of diagnostic measurements in the energy sector. The advantage of this method in comparison with the commonly used system of measurements of concentrations of gaseous components in flue gases at one point of flue gas ducting is its higher accuracy in the determination of the average value of concentration at the output from incineration sources, and the corresponding lower uncertainty in determining the efficiency of these devices.
\end{abstract}

Keywords-diagnostic measurement; continuous network sampling; concentration of gaseous component; flue gases; efficiency

\section{INTRODUCTION}

To assess the optimum operation of incineration sources, it is necessary to verify the designed parameters of the devices in real operating conditions, which is why there is a large area of diagnostic measurements, having its own characteristic features.

Certain non-stationary character of the technological process is almost always an essential feature of the measurements in industrial energy facilities. Only few boilers, especially in thermal power station application, are run in a stationary mode. The steam power output normally fluctuates within a relatively wide range, and there are also relatively frequent changes in the qualitative characteristics of the fuel, which is related to the volatility of the quantity and properties of flue gases. The issue of the determination of the amount of flue gases and their composition is therefore a separate chapter of diagnostic measurements during the evaluation of efficiency [1].

\section{CurRent State OF TEChNOLOGY}

The determination of the average concentration of gaseous pollutants in flue gases at the boiler output usually requires their analysis, using an extractive method based on sampling of flue gases from the flue gas ducting $[2,3]$. There are two methods of measurement of their concentrations which can be described as continuous and single method.
Continuous monitoring, which is required by the legislation [4], is equipped with operating measuring instruments [5] and is based on sampling of flue gases from one point in the cross-section of the flue gas ducting. The final value does not include any eventual uneven character of the concentration field at the measuring point.

The area of diagnostic measurements takes advantage of single measurement of concentrations, which is performed on the basis of sampling of flue gases from several points around the flue gas ducting cross-section, whose number is given by the location of the measuring profile, its shape and dimensions [6]. At present, the sampling is usually carried out by means of the single method, and this sampling requires an apparatus consisting of a single probe, air-tight fan and plastic sample containers. The analysis of the samples of flue gases takes place after the completion of the sampling, resulting in a possible omission of an eventual change in the composition of the flue gases in relation to time, which is a disadvantage of this determination method.

A new apparatus for continuous network sampling and the methodology of its application refine the existing results of the single diagnostic measurements, and the analysis takes place in real time and thus takes into account the dependence of the concentration of the monitored gaseous components on the operating state of the incineration plant, in particular, on the change of performance and fuel, and it also includes any eventual non-uniformity of the concentration field at the point of measurement.

\section{THE BASIS OF THE TECHNICAL SOLUTION}

The apparatus for continuous network sampling and the analysis of selected gaseous components of flue gases is assembled from several sampling branches with a multiopening sampling probe. Each probe is connected via a sampling pipeline through a condensate separator and a solid impurities filter to a control flow meter. The control flow meters outputs are connected to a gas mixing chamber, from which the flue gas sample is transported, after mixing, to a continuous analyzer by means of a diaphragm pump (refer with: Figure 1). 


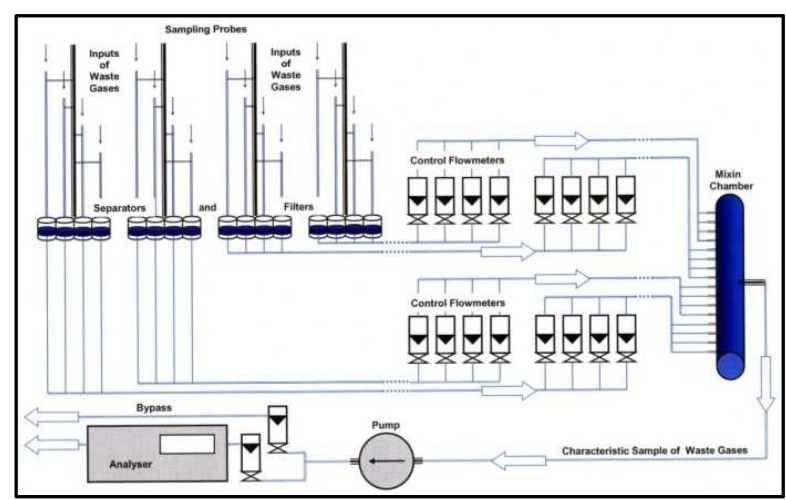

FIGURE I. SCHEME OF THE APPARATUS FOR CONTINUOUS NETWORK SAMPLING

The analysis result is the value of the average concentration of the monitored gaseous component, depending on the type of used analyzer $\left(\mathrm{CO}, \mathrm{NO}_{\mathrm{x}}, \mathrm{O}_{2}\right)$, in the flue gases flowing through flue gas ducting of large sizes, fitted on the outlets from the thermal power plant boilers.

The concentrations of gaseous pollutants in the individual measuring points in the flue gas ducting cross-section, necessary to create a concentration profile and to find its potential fluctuations, can be determined through appropriate manipulation of the control flow metres of the used apparatus [7].

This measurement method also makes it possible to determine the concentration of the monitored gaseous pollutants as a weighted average of the measured values of velocities and concentrations in the individual measuring points along the cross-section of the flue gas ducting, as indicated below.

\section{A. Experimental Determination of Flow Velocity and the Amount of Fluegases}

The flow velocity of flue gases (wi) is measured at the same measuring n-points in the flue gas ducting cross-section, where the measurement of the $\mathrm{O} 2$ content [6] is performed.

The measurement of flue gas velocity takes advantage either of a vane anemometer, enabling you to measure directly the velocities of gas flows up to $250{ }^{\circ} \mathrm{C}$ (range of $0 \div 23 \mathrm{~m} / \mathrm{s}$ with the resolution of $0.1 \mathrm{~m} / \mathrm{s}$ ), or a Prandtl probe connected to a digital micro-manometer with the evaluation of the dynamic flue gases pressure, and subsequent calculation of the flow velocity. The values of arithmetic (wa) and weighted average (wv) of flow velocity of flue gases in flue gas ducting can be determined according to Eq. 1 or Eq.2:

$$
\begin{array}{ll}
\mathrm{w}_{\alpha}=\frac{\sum_{\mathrm{i}=1}^{\mathrm{n}} \mathrm{w}_{\mathrm{i}}}{\mathrm{n}} & {[\mu / \sigma]} \\
\mathrm{w}_{\mathrm{v}}=\frac{\sum_{\mathrm{i}=1}^{\mathrm{n}} \mathrm{s}_{\mathrm{i}} \cdot \mathrm{w}_{\mathrm{i}}}{\sum_{\mathrm{i}=1}^{\mathrm{n}} \mathrm{s}_{\mathrm{i}}} & {[\mu / \sigma]}
\end{array}
$$

The measured values of flue gas velocity at the individual points can be used to calculate the values of the amount of flue gases flowing through the individual surfaces ( $\mathrm{Si}$ ), corresponding to the distribution of the measuring points along the flue gas ducting cross-section, and to determine the value of weighted average of the amount of flue gases $\left(\mathrm{V}_{\mathrm{EFv}}\right)$ as follows Eq.3:

$$
\mathrm{V}_{\mathrm{EFv}}=\sum_{\mathrm{i}=1}^{\mathrm{n}} \mathrm{S}_{\mathrm{i}} \cdot \mathrm{w}_{\mathrm{i}} \quad[\mathrm{m} 3 / \mathrm{s}]
$$

\section{B. Experimental Determination of the Average Concentration of Gaseous Pollutants}

The measurement of the content of gaseous pollutants in flue gases at the boiler outlet is also carried out in compliance with the network method, at the same measuring points as during the flue gas velocity measurement [6].

The continuous sampling of flue gas sample from multiple points (network sampling) along the flue gas ducting crosssection and its real-time analysis is an objective solution for the determination of the average concentration of the selected flue gas components. The necessary manipulation with shutoff valves of the control flow meters (see Fig no. 1) allows you to observe the concentration of pollutants at the individual points along the flue gas ducting cross-section.

The average values of the concentrations of the measured gaseous components of flue gases at the individual measuring points along the flue gas ducting cross-section $\left(\mathrm{X}_{\mathrm{i}}\right)$, gathered during the entire measurement time by means of an apparatus for continuous network sampling, are used to determine the value of arithmetic $\left(\mathrm{X}_{\mathrm{a}}\right)$ and weighted average of the concentration of gaseous pollutants in flue gases $\left(X_{v}\right)$, according to Eq.4 or Eq.5:

$$
\begin{array}{cr}
\mathrm{X}_{\mathrm{a}}=\frac{\sum_{\mathrm{i}=1}^{\mathrm{n}} \mathrm{X}_{\mathrm{i}}}{\mathrm{n}} & {[\%, \mathrm{ppm}]} \\
\mathrm{X}_{\mathrm{V}}=\frac{\sum_{\mathrm{i}=1}^{\mathrm{n}} \mathrm{X}_{\mathrm{i}} \cdot \mathrm{w}_{\mathrm{i}}}{\sum_{\mathrm{i}=1}^{\mathrm{n}} \mathrm{w}_{\mathrm{i}}} & {[\%, \mathrm{ppm}]}
\end{array}
$$

\section{PROCESSING OF THE MEASURED VARIABLES AND THE REFERENCE POINT DETERMINATION}

An objective determination of the average concentrations of the monitored gaseous pollutants in flue gases at the boiler outlet requires monitoring of the whole boiler performance range during the diagnostic measurements, in order to always identify several conditions in collaboration with the operator, which are most frequently used to run the equipment. The selection must take into account not only the required performance, but often also the ratio of the incinerated fuels.

Generally, the higher the number of operating conditions to be monitored, the more objective the result of an experimental determination of the average concentration. $3 \div 6$ operating conditions (modes) are usually monitored in real situations in the entire performance range of the equipment. The results of the measurements and calculations for the individual modes can be presented in different ways, depending on the assignment. However, a tabular overview of the weighted averages of the monitored variables, in connection with the measured values at the individual measuring points along the flue gas ducting cross-section, are always crucial. A mutual comparison of the tables, compiled for the individual 
measurement modes, allows you to establish a reference point in the flue gas ducting.

A reference point in the flue gas ducting is therefore a place (measuring point) in the flue gas ducting cross-section, in which the measured variables of the monitored flue gases parameters (concentrations of gaseous components) are closest to the values of their weighted average, with the highest number of monitored modes.

\section{CONCLUSION}

The presented article describes the issue of an experimental determination of a reference point in the flue gas ducting used to determine the concentration of gaseous components in flue gases at the boiler outlet in flue gas ducting of larger dimensions. It is an area that is always included in boiler diagnostic measurements in order to determine its thermal efficiency.

It is obvious that the resulting value of thermal efficiency may be significantly influenced by an incorrect determination of the concentration of gaseous components of flue gases, in particular the concentrations of $\mathrm{O} 2$, because it results in an inaccurately defined amount of flue gases and the chimney loss, which is the largest heat loss during the operation of boilers [1]

The use of the above specified apparatus for continuous network sampling of flue gas sample and its analysis is currently the most accurate method of determination of the average concentrations of gaseous components of flue gases and a reference point in flue gas ducting. Its application for diagnostic measurements can make the result more accurate by up to a few percents [7].

The results of such accurate measurements during the experimental determination of the average flue gas parameters and finding a reference point prevent incorrect placement of operating control system sensors in an unsuitable place in the flue gas ducting, which results in non-optimal operation of the boiler, higher amount of gaseous pollutants released into the atmosphere and, last but not least, irregularities in the thermal balances. With regards to these facts, it is very important to pay due attention to the experimental determination of the flue gas parameters in real operating conditions and the subsequent selection of a reference point in the flue gas ducting crosssection, because it will pay off many times.

\section{REFERENCES}

[1] ČSN 070305 Evaluation of boiler losses. ČNI Prague 1983.

[2] RAJNIAK I.: Thermal-energy and emission measurements. Bratislava 1997, ISBN 80-88683-20-3.

[3] LACKNER M., WINTER F., AGARWAL K.A.: Handbook of combustion - Volume 2: Combustion Diagnostics and Pollutants. Weinheim 2010. ISBN 978-3-527-32449-1

[4] Act of the MoE of the CR no.201/2012 of the Coll. on Air Protection.

[5] BARTOVSKÝ T.: Emission analyzer. VUSTE Servis s.p., Prague, 1994.

[6] ČSN ISO 9096: Stationary emission sources - Determination of mass concentration and mass flow of solid particles in a pipeline - manual gravimetric method. ČNI Prague 1998.

[7] VÝTISK T.: The apparatus for continuous network sampling and analysis of some gas components of waste gases, The apparatus technical design - utility model - no. PUV 2010-22417, The office of industrial ownership Prag, 2010. 